\title{
Factors Related to Body Mass Index and Body Mass Index Change in Korean Children: Preliminary Results from the Obesity and Metabolic Disorders Cohort in Childhood

\section{Hyun Hye Lee, Hyun Ah Park*, Jae Heon Kang, Young Gyu Cho, Jin Kyun Park ${ }^{1}$, Ran Lee ${ }^{2}$, Ji Ye Yoon, Ok Hyun Kim ${ }^{3}$}

Department of Family Medicine, Inje University College of Medicine; ${ }^{1}$ Department of Internal Medicine, Seoul National University Hospital, Seoul National University College of Medicine; ${ }^{2}$ Department of Pediatrics, Konkuk University School of Medicine; ${ }^{3}$ Institute for Clinical Nutrition, Inje University, Seoul, Korea

Background: This preliminary study is to assess risk factors associated with children's body mass index (BMI) and their changes over a 2-year period based on the analysis of the Obesity and Metabolic Disorders Cohort in Childhood registry.

Methods: A total of 1,504 children comprised of 474 1st graders and 1,030 4th graders were included in the study. Data on physical activity, dietary intake, and socioeconomic status were obtained through self-administered questionnaires, and height and weight were measured annually for 2 years.

Results: In a cross-sectional analysis, BMI of 1st graders was associated with higher parental BMI (both $\mathrm{P}<0.001)$ and frequent snack consumption $(\mathrm{P}=0.049)$. $\mathrm{BMI}$ of 4 th graders was additionally associated with shorter sleep duration $(\mathrm{P}=$ 0.001), lower household income $(\mathrm{P}=0.016)$, higher fat intake $(\mathrm{P}=0.017)$, and frequent meal skipping $(\mathrm{P}=0.020)$. During a 2-year follow-up, BMI increased by $0.8 \pm 1.4 \mathrm{~kg} / \mathrm{m}^{2}$ in 1 st graders and by $1.3 \pm 1.4 \mathrm{~kg} / \mathrm{m}^{2}$ in 4 th graders. In a longitudinal analysis, higher exercise frequency $(\mathrm{P}=0.007)$, shorter sleep duration $(\mathrm{P}=0.027)$, lower household income $(\mathrm{P}=0.002)$, and higher paternal BMI $(\mathrm{P}=0.002,0.043)$ were significant predictors of BMI changes in the 1st graders whereas only higher maternal BMI $(\mathrm{P}=0.035)$, and frequent snack consumption $(\mathrm{P}=0.010)$ were predictors for the 4 th graders $\mathrm{BMI}$ changes.

Conclusion: Our findings indicate that parental obesity, short sleep duration, low socioeconomic status, and frequent snacking are associated with BMI and BMI changes.

Keywords: Body Mass Index; Child; Motor Activity; Diet; Environment

\section{INTRODUCTION}

Received: August 31, 2011, Accepted: May 7, 2012

*Corresponding Author: Hyun Ah Park

Tel: 82-2-2270-0952, Fax: 82-2-2267-2030

E-mail: drparkhyunah@gmail.com

Korean Journal of Family Medicine

Copyright (C) 2012 The Korean Academy of Family Medicine

(a) This is an open-access article distributed under the terms of the Creative Commons Attribution Non-Commercial License (http://creativecommons.org/licenses/by-nc/3.0) which permits unrestricted noncommercial use, distribution, and reproduction in any medium, provided the original work is properly cited.

The prevalence of obesity has increased at an alarming rate not only in adults but also in Korean children. ${ }^{1)}$ Korea is not an exception, with the proportion of obese children increasing from $5.8 \%$ in 1997 to $9.7 \%$ in $2005^{2)}$

There is now an emerging body of evidence that childhood obesity often persists into adulthood, ${ }^{3)}$ underscoring the importance of management, prevention, and treatment of childhood obesity. A higher success rate of obesity treatment 
for children vs. adults and the possibility of long lasting lifestyle modification in children make early intervention aiming at modifying risk factors a top priority.

For these reasons, many longitudinal studies have been conducted overseas to investigate the risk factors for childhood obesity, ${ }^{5-7)}$ and there are active discussions on effective interventions for confirmed risk factors. ${ }^{89}$ ) The awareness of the significance of childhood obesity has risen gradually in Korea as well, with many studies being conducted. However, most of the studies are cross-sectional in nature, ${ }^{10,11)}$ and more longitudinal studies are needed as cross-sectional studies have limitations in clearly identifying causal and temporal relationships.

In this preliminary study, we show the factors that are associated with children's body mass index (BMI) and its changes over a 2-year period, analyzing the Obesity and Metabolic Disorders Cohort in Childhood registry.

\section{METHODS}

\section{The Obesity and Metabolic Disorders Cohort in Childhood and Study Participants}

The Obesity and Metabolic Disorders Cohort in Childhood is a prospective dynamic cohort study that performs annual follow-ups aimed at determining the prevalence, causes, prevention, and management of childhood obesity. At baseline in 2005 , the cohort included all 1st graders of 4 elementary schools in Gwacheon city, a suburb city of Seoul. In 2008, in the 4th year follow-up, 1st and 4th graders from 2 elementary schools in Junggu, downtown Seoul, and 5 elementary schools in Gyeonggi province were added to the cohort. Annual physical examinations including anthropometry, blood chemistry, and questionnaires on lifestyle habits including diet were administered (Figure 1). This study was approved by the institutional review board of Inje University Seoul Paik Hospital. A detailed description on this cohort is given elsewhere. ${ }^{12)}$

An analytic sample included in total 1,504 children who participated in both of the 4th (2008) and 6th (2010) annual follow-ups. Baseline characteristics including age, height, weight, BMI, and household income were not significantly different between participants in our analytic sample who underwent both of the 4th and 6th follow-ups and participants who underwent only the 4th follow-up. However, there were more girls (62.3\%) who were followed up on compared to boys $(56.0 \%)$ in 4 th

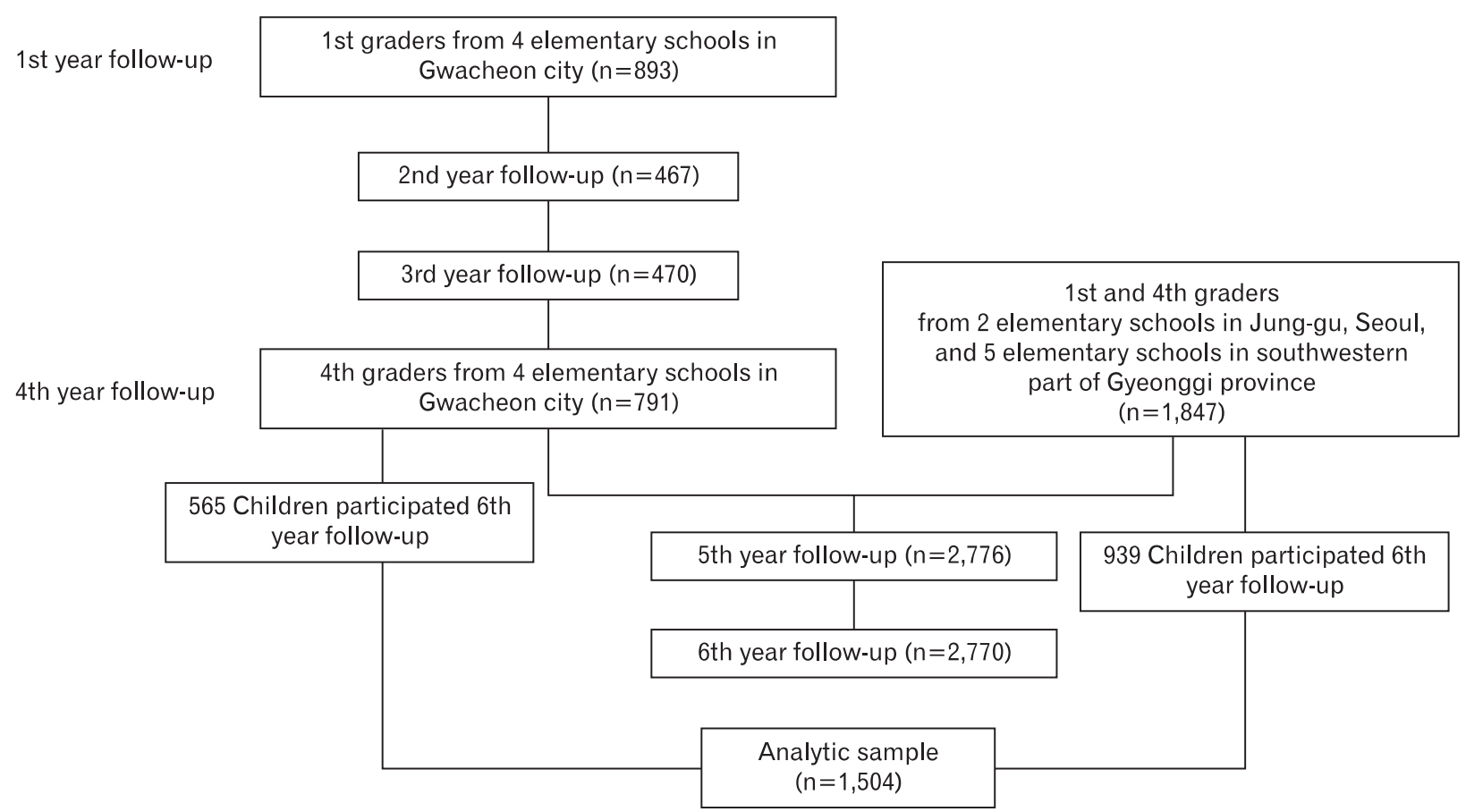

Figure 1. The flow chart of the Obesity and Metabolic Disorders Cohort in Childhood. This study included in total 1,504 children who participated in both of the 4th (2008) and 6th (2010) annual follow-ups. 
graders $(\mathrm{P}=0.007)$.

\section{Anthropometric Measurement and Obesity Definition}

Height and weight of the participants were measured by trained researchers using a manual height scale (DS-102; Jenix, Seoul, Korea) and bioelectrical body composition analyzer (BC418; Tanita Co., Tokyo, Japan). BMI was calculated by weight (kg) divided by height, squared $\left(\mathrm{m}^{2}\right)$. The BMI percentile was estimated based on the age and sex-specific 2007 growth chart for Korean children. ${ }^{13)}$ Pubertal stages were assessed by the Tanner stages. Children and their parents were asked to select the pubertal rating that best indicated his or her own development by self-assessment.

\section{Physical Activity Measurement}

Data on physical activity were obtained through selfadministered questionnaires. Children and their parents were asked to fill out the questionnaires together. Exercise frequency per week was calculated by summing up days with moderate physical activity of more than 30-minute duration or vigorous physical activity of more than 20-minute duration. Moderate physical activity was defined as activity that increased respiratory rate noticeably, while vigorous physical activity was defined as activity associated with shortness of breath or increased perspiration. Sleep duration was calculated as the mean of reported sleep time per day over one week. Screen time was defined as duration spent watching television plus using the computer per day.

\section{Socioeconomic Factors and Parental Factors}

The mean monthly household income was ascertained through a questionnaire. Education level of parents was categorized into three groups: equal or less than 12 years of schooling, between 13 to 16 years of schooling, and equal or more than 17 years of schooling. Data on family structure and maternal job status were collected as well. Parental BMI was calculated by their reported weight and height and was then classified as normal $\left(<23 \mathrm{~kg} / \mathrm{m}^{2}\right)$, overweight (more than $23 \mathrm{~kg} / \mathrm{m}^{2}$ and under 25 $\left.\mathrm{kg} / \mathrm{m}^{2}\right)$, or obese $\left(\geq 25 \mathrm{~kg} / \mathrm{m}^{2}\right)$, according to the standards of the Korean Society for the Study of Obesity.
Table 1. Baseline characteristics of study participants.

\begin{tabular}{|c|c|c|}
\hline Variables & $\begin{array}{l}\text { 1st grade } \\
(\mathrm{n}=474)\end{array}$ & $\begin{array}{l}\text { 4th grade } \\
(\mathrm{n}=1,030)\end{array}$ \\
\hline Sex (male) & $226(47.7)$ & $508(49.3)$ \\
\hline Age (y) & $7.3 \pm 0.3$ & $10.0 \pm 0.4$ \\
\hline BMI $\left(\mathrm{kg} / \mathrm{m}^{2}\right)$ & $16.0 \pm 2.3$ & $18.1 \pm 3.0$ \\
\hline \multicolumn{3}{|l|}{ BMI percentile } \\
\hline$\leq 10.0$ & $43(9.1)$ & $35(3.5)$ \\
\hline $10.1-84.9$ & 374 (78.9) & $816(79.2)$ \\
\hline $85-94.9$ & $36(7.6)$ & $110(10.6)$ \\
\hline$\geq 95.0$ & $21(4.4)$ & $69(6.7)$ \\
\hline \multicolumn{3}{|l|}{ Exercise (frequency/wk) } \\
\hline$\leq 1$ & $128(27.0)$ & $321(31.2)$ \\
\hline $2-4$ & $266(56.1)$ & $576(55.9)$ \\
\hline$\geq 5$ & $80(16.9)$ & $133(12.9)$ \\
\hline Screen time $(\mathrm{h} / \mathrm{d})$ & $1.4 \pm 0.8$ & $1.6 \pm 1.0$ \\
\hline Sleep hour (h/d) & $9.0 \pm 0.6$ & $8.7 \pm 0.7$ \\
\hline Household income $>3$ million KRW & 372 (78.5) & $641(62.2)$ \\
\hline Maternal BMI $\left(\mathrm{kg} / \mathrm{m}^{2}\right)$ & $21.3 \pm 2.4$ & $21.7 \pm 2.5$ \\
\hline$<23$ & $384(81.0)$ & $781(75.8)$ \\
\hline $23-24.9$ & $55(11.6)$ & $155(15.0)$ \\
\hline$\geq 25$ & $35(7.4)$ & $94(9.1)$ \\
\hline Paternal BMI (kg/m²) & $23.7 \pm 2.7$ & $23.8 \pm 2.5$ \\
\hline$<23$ & $173(36.5)$ & $380(36.9)$ \\
\hline $23-24.9$ & $171(36.1)$ & $382(37.1)$ \\
\hline$\geq 25$ & $130(27.4)$ & $268(26.0)$ \\
\hline \multicolumn{3}{|l|}{ Maternal education (y) } \\
\hline$\leq 12$ & $152(32.1)$ & $363(35.2)$ \\
\hline $13-16$ & $300(63.3)$ & $602(58.4)$ \\
\hline$\geq 17$ & $22(4.6)$ & $65(6.3)$ \\
\hline \multicolumn{3}{|l|}{ Paternal education (y) } \\
\hline$\leq 12$ & $96(20.3)$ & $265(25.7)$ \\
\hline $13-16$ & $323(68.1)$ & $605(58.7)$ \\
\hline$\geq 17$ & $55(11.6)$ & $160(15.5)$ \\
\hline Working mother & $177(37.3)$ & $441(42.8)$ \\
\hline Family structure, two parents & 450 (94.9) & $883(85.7)$ \\
\hline Total energy intake (1,000 kcal/d) & $1.8 \pm 0.3$ & $1.7 \pm 0.4$ \\
\hline Fat \% of energy intake (\%) & $26.6 \pm 4.9$ & $25.2 \pm 5.1$ \\
\hline Meal skipping during a week & $131(27.6)$ & $287(27.9)$ \\
\hline Snack intake & $110(23.2)$ & 232 (22.5) \\
\hline
\end{tabular}

Values are presented as number (\%) or mean \pm SD. BMI: body mass index, KRW: Korean won. 


\section{Dietary Habit, Dietary Intake Survey}

The frequency of skipping meals and snack intake was reported. Dietary intake was recorded for two weekdays and one day on the weekend by a 24-hour recall method. This information was then converted into nutrient intake by computer aided nutrients analysis program 2006 (CAN-Pro 3.0; Korean Nutrition Society, Seoul, Korea) from the Korean Nutrition Society.

\section{Statistical Analysis}

A stratified analysis was conducted for 1st graders and 4th graders separately. Continuous variables were expressed as mean and standard deviation and categorical variables were presented as numbers and percentages. The ANOVA test and t-test were used for comparisons of demographic characteristics.

Table 2. Anthropometric change during a 2-year follow-up period.

\begin{tabular}{|c|c|c|}
\hline Mean \pm SD & 1st grade $(\mathrm{n}=474)$ & 4 th grade $(n=1,030$ \\
\hline \multicolumn{3}{|l|}{ Weight (kg) } \\
\hline Baseline & $25.0 \pm 4.7$ & $35.6 \pm 7.8$ \\
\hline Follow-up & $30.0 \pm 5.9$ & $44.7 \pm 9.2$ \\
\hline Change & $4.9 \pm 2.8$ & $9.1 \pm 3.7$ \\
\hline \multicolumn{3}{|l|}{ Height $(\mathrm{cm})$} \\
\hline Baseline & $124.8 \pm 5.0$ & $139.7 \pm 6.2$ \\
\hline Follow-up & $133.2 \pm 5.4$ & $151.3 \pm 6.6$ \\
\hline Change & $8.4 \pm 1.7$ & $11.6 \pm 2.9$ \\
\hline \multicolumn{3}{|l|}{ BMI $\left(\mathrm{kg} / \mathrm{m}^{2}\right)$} \\
\hline Baseline & $16.0 \pm 2.3$ & $18.1 \pm 3.0$ \\
\hline Follow-up & $16.8 \pm 2.5$ & $19.4 \pm 3.2$ \\
\hline Change & $0.8 \pm 1.4$ & $1.3 \pm 1.4$ \\
\hline \multicolumn{3}{|l|}{ BMI percentile } \\
\hline \multicolumn{3}{|l|}{ Baseline } \\
\hline$\leq 10.0$ & $43(9.1)$ & $42(8.8)$ \\
\hline $10.1-84.9$ & 374 (78.9) & $380(80.2)$ \\
\hline $85.0-94.9$ & $36(7.6)$ & $29(6.1)$ \\
\hline$\geq 95.0$ & $21(4.4)$ & $23(4.9)$ \\
\hline \multicolumn{3}{|l|}{ Follow-up } \\
\hline$\leq 10.0$ & $35(3.4)$ & $32(3.1)$ \\
\hline $10.1-84.9$ & $816(79.2)$ & $827(80.3)$ \\
\hline $85-94.9$ & $110(10.6)$ & $110(10.7)$ \\
\hline$\geq 95.0$ & $69(6.7)$ & $61(5.9)$ \\
\hline
\end{tabular}

We analyzed data both cross-sectionally and longitudinally. Multiple linear regression modeling was used to estimate coefficients and confidential interval (CI). Predictor variables for the models were environmental factors, parental and lifestyle habits, whereas dependent variables were BMI in the 4th annual follow-up survey for the cross-sectional analysis, and the BMI changes between 4th and 6th year follow-ups for longitudinal analysis. We additionally adjusted the BMI in the 4th survey only for longitudinal analysis. The estimated BMI changes by parental obesity degree were calculated using general linear modeling. All statistical analyses were performed with SPSS ver. 18 (SPSS Inc., Chicago, IL, USA) and values with $\mathrm{P}<0.05$ were considered statistically significant.

\section{RESULTS}

\section{Baseline Characteristics of Study Population}

Our study cohort included 474 1st graders (31.5\%) and 1,030 4th graders $(68.5 \%)$. Mean ages were $7.3 \pm 0.3$ years and $10.0 \pm$ 0.4 years, respectively. The mean BMI of the 1st graders was 16.0 $\pm 2.3 \mathrm{~kg} / \mathrm{m}^{2}$ with $12.0 \%$ being over 85 percentile of BMI curve, whereas the mean BMI of the 4th graders was $18.1 \pm 3.0 \mathrm{~kg} / \mathrm{m}^{2}$ with $17.3 \%$ having the corresponding figure. Data on physical activity, socioeconomic status, family history, dietary habits, and dietary intake of participants are presented in Table 1.

\section{Anthropometric Changes over 2 Years}

During a 2-year follow-up, the mean weight of the 1st graders increased by $4.9 \pm 2.8 \mathrm{~kg}$, and height by $8.4 \pm 1.7 \mathrm{~cm}$. 4th graders' weight increased by $9.1 \pm 3.7 \mathrm{~kg}$ and height by $11.6 \pm 2.9 \mathrm{~cm}$. BMI increased by $0.8 \pm 1.4 \mathrm{~kg} / \mathrm{m}^{2}$ in 1st graders, and $1.3 \pm 1.4 \mathrm{~kg} / \mathrm{m}^{2}$ in 4 th graders. At the 6 th year follow-up, the proportions of children having BMI percentile over 85 were $17.3 \%$ for 1 st graders, and $16.6 \%$ for 4 th graders (Table 2 ).

\section{Factors Influencing BMI at Baseline and BMI Changes over 2 Years for 1st Graders}

In a cross-sectional analysis, BMI of children increased by $0.181 \mathrm{~kg} / \mathrm{m}^{2}$ as maternal BMI increased by $1 \mathrm{~kg} / \mathrm{m}^{2}(\mathrm{P}<0.001)$ after adjustment of covariates. Higher paternal BMI was also significantly associated with higher $\mathrm{BMI}$ in children $(\mathrm{P}<0.001)$. 
Table 3. Multivariate linear regression modeling for baseline BMI and 2 years BMI change of the 1st graders.

\begin{tabular}{|c|c|c|c|c|}
\hline \multirow{2}{*}{ Variables } & \multicolumn{2}{|c|}{ Baseline BMI $\left(\mathrm{kg} / \mathrm{m}^{2}\right)^{\dagger}$} & \multicolumn{2}{|c|}{ BMI change $\left(\mathrm{kg} / \mathrm{m}^{2}\right)$ during 2 year follow-up ${ }^{\ddagger}$} \\
\hline & Coefficients $(95 \% \mathrm{CI})$ & P-value & Coefficients (95\% CI) & P-value \\
\hline \multicolumn{5}{|l|}{ Exercise frequency per week (vs. < 1) } \\
\hline $2-4$ & $-0.056(-0.508$ to 0.396$)$ & 0.807 & 0.354 ( 0.075 to 0.632$)$ & $0.013^{*}$ \\
\hline$\geq 5$ & $-0.047(-0.738$ to 0.644$)$ & 0.893 & 0.587 (0.161 to 1.014$)$ & $0.007^{* *}$ \\
\hline Weekly screen time per an hour & $-0.012(-0.051$ to 0.026$)$ & 0.535 & $0.014(-0.009$ to 0.038$)$ & 0.235 \\
\hline \multicolumn{5}{|l|}{ Sleep duration (h) per day (vs. $\leq 8.5$ ) } \\
\hline $8.5-9.5$ & $-0.310(-0.882$ to 0.261$)$ & 0.286 & $-0.192(-0.543$ to 0.159$)$ & 0.284 \\
\hline$\geq 9.5$ & -0.508 ( -1.173 to 0.157$)$ & 0.134 & $-0.463(-0.871$ to -0.054$)$ & $0.027^{*}$ \\
\hline Household income ( $\leq 3$ million vs. $>3$ million KRW) & -0.377 ( -1.319 to 0.565$)$ & 0.432 & $-0.854(-1.402$ to -0.307$)$ & $0.002^{* *}$ \\
\hline Maternal BMI per $1 \mathrm{~kg} / \mathrm{m}^{2}$ & 0.181 (0.096 to 0.265$)$ & $<0.001^{* * *}$ & 0.083 (0.030 to 0.137$)$ & $0.002^{* *}$ \\
\hline Paternal BMI per $1 \mathrm{~kg} / \mathrm{m}^{2}$ & 0.169 (0.094 to 0.243 ) & $<0.001^{* * *}$ & 0.043 (0.002 to 0.095$)$ & $0.043^{*}$ \\
\hline \multicolumn{5}{|l|}{ Maternal education (vs. < 12 y) } \\
\hline $13-16$ & $-0.004(-0.522$ to 0.513$)$ & 0.987 & $0.015(-0.303$ to 0.334$)$ & 0.925 \\
\hline$\geq 17$ & $-0.098(-1.195$ to 1.000$)$ & 0.861 & $-0.507(-1.183$ to 0.170$)$ & 0.142 \\
\hline \multicolumn{5}{|l|}{ Paternal education (vs. < 12 y) } \\
\hline $13-16$ & $-0.448(-1.053$ to 0.156$)$ & 0.146 & 0.113 ( -0.260 to 0.485$)$ & 0.552 \\
\hline$\geq 17$ & $-0.086(-0.951$ to 0.779$)$ & 0.844 & $0.399(-0.134$ to 0.931$)$ & 0.142 \\
\hline Maternal job (yes vs. no) & $-0.081(-0.507$ to 0.345$)$ & 0.708 & $0.228(-0.035$ to 0.491$)$ & 0.089 \\
\hline Family structure (two parents vs. single) & $-0.238(-1.341$ to 0.864$)$ & 0.671 & $-0.082(-0.747$ to 0.584$)$ & 0.809 \\
\hline Energy intake per a 1,000 kcal & $-0.031(-0.117$ to 0.055$)$ & 0.481 & $0.027(-0.026$ to 0.080$)$ & 0.322 \\
\hline Fat \% of energy intake per a percent & 0.017 ( -0.023 to 0.057$)$ & 0.408 & $0.021(-0.004$ to 0.046$)$ & 0.104 \\
\hline Meal skipping during a week (yes vs. no) & 0.038 ( -0.017 to 0.093$)$ & 0.170 & $0.021(-0.013$ to 0.055$)$ & 0.232 \\
\hline Snack (yes vs. no) & 0.467 (0.003 to 0.931$)$ & $0.049^{*}$ & $0.189(-0.098$ to 0.476$)$ & 0.196 \\
\hline
\end{tabular}

BMI: body mass index, CI: confidential interval, KRW: Korean won.

${ }^{*} \mathrm{P}<0.05 .{ }^{* *} \mathrm{P}<0.01$. ${ }^{* * *} \mathrm{P}<0.001$.

${ }^{\dagger}$ Adjusted for age (continuous), sex (male or female), sexual maturation at 4th year follow-up (Tanner stage I, II, III, IV, V), and variables in this table. ${ }^{\ddagger}$ Adjusted for age (continuous), sex (male or female), sexual maturation at 6 th year follow-up (Tanner stage I, II, III, IV, V), baseline BMI (continuous), and variables in this table.

Children who had snacks had a higher BMI by $0.467 \mathrm{~kg} / \mathrm{m}^{2}$ as compared with those who didn't $(\mathrm{P}=0.049)$.

In the longitudinal study with BMI change as an outcome variable, exercise $(P=0.013, P=0.007)$, sleep duration ( $P$ $=0.027)$, household income $(P=0.002)$, maternal BMI $(P$ $=0.002)$, and paternal BMI $(P=0.043)$ were all significant predictors of $\mathrm{BMI}$ increase. In particular, children reporting more than 9.5 hours of sleep per day experienced a lower BMI increase by 0.463 (CI, 0.054 to 0.871$) \mathrm{kg} / \mathrm{m}^{2}$ than children reporting less than 8.5 hours of sleep duration. Monthly household income more than 3,000,000 Korean won (approximately 2,800 US dollar) was a significant protective factor for a BMI increase by 0.854 (CI, 0.307 to 1.402$) \mathrm{kg} / \mathrm{m}^{2}$ (Table 3).

\section{Factors Influencing BMI at Baseline and BMI Changes over 2 Years for 4th Graders}

In the cross-sectional analysis, for every maternal BMI increase of $1 \mathrm{~kg} / \mathrm{m}^{2}$, children's BMI increased by $0.208 \mathrm{~kg} / \mathrm{m}^{2}$ $(\mathrm{P}<0.001)$. Higher paternal BMI $(\mathrm{P}<0.001)$, shorter sleep duration ( $P=0.001)$, lower household income $(P=0.016)$, 
Table 4. Multivariate linear regression modeling for baseline BMI and 2 years BMI change of the 4th graders.

\begin{tabular}{|c|c|c|c|c|}
\hline \multirow{2}{*}{ Variables } & \multicolumn{2}{|c|}{ Baseline BMI $\left(\mathrm{kg} / \mathrm{m}^{2}\right)^{\dagger}$} & \multicolumn{2}{|c|}{ BMI change $\left(\mathrm{kg} / \mathrm{m}^{2}\right)$ during 2 year follow-up } \\
\hline & Coefficients (95\% CI) & P-value & Coefficients (95\% CI) & P-value \\
\hline \multicolumn{5}{|l|}{ Exercise frequency per week (vs. < 1) } \\
\hline $2-4$ & $0.034(-0.343$ to 0.410$)$ & 0.860 & $0.091(-0.104$ to 0.285$)$ & 0.361 \\
\hline$\geq 5$ & $-0.138(-0.812$ to 0.536$)$ & 0.688 & $0.199(-0.150$ to 0.547$)$ & 0.263 \\
\hline Weekly screen time per an hour & $-0.002(-0.027$ to 0.023$)$ & 0.876 & -0.004 ( -0.016 to 0.009$)$ & 0.584 \\
\hline \multicolumn{5}{|l|}{ Sleep duration (h) per day (vs. $\leq 8.5$ ) } \\
\hline $8-9$ & $-0.143(-0.612$ to 0.326$)$ & 0.551 & $-0.079(-0.321$ to 0.162$)$ & 0.520 \\
\hline$\geq 9$ & $-0.852(-1.356$ to -0.348$)$ & $0.001^{* *}$ & 0.024 ( -0.236 to 0.285$)$ & 0.855 \\
\hline Household income ( $\leq 3$ million vs. $>3$ million KRW) & $-0.632(-1.144$ to -0.120$)$ & $0.016^{*}$ & $-0.018(-0.283$ to 0.247$)$ & 0.894 \\
\hline Maternal BMI per $1 \mathrm{~kg} / \mathrm{m}^{2}$ & $0.208(0.140$ to 0.276$)$ & $<0.001^{* * *}$ & 0.038 (0.003 to 0.074$)$ & $0.035^{*}$ \\
\hline Paternal BMI per $1 \mathrm{~kg} / \mathrm{m}^{2}$ & 0.234 (0.166 to 0.302$)$ & $<0.001^{* * *}$ & $0.028(-0.009$ to 0.064$)$ & 0.135 \\
\hline \multicolumn{5}{|l|}{ Maternal education (vs. < 12 y) } \\
\hline $13-16$ & -0.162 ( -0.614 to 0.291$)$ & 0.484 & -0.167 ( -0.401 to 0.067$)$ & 0.161 \\
\hline$\geq 17$ & $-0.020(-0.832$ to 0.791$)$ & 0.961 & -0.077 ( -0.496 to 0.342$)$ & 0.718 \\
\hline \multicolumn{5}{|l|}{ Paternal education (vs. < 12 y) } \\
\hline $13-16$ & $-0.016(-0.505$ to 0.473$)$ & 0.946 & -0.048 ( -0.300 to 0.205$)$ & 0.711 \\
\hline$\geq 17$ & $0.117(-0.540$ to 0.774$)$ & 0.727 & $0.055(-0.284$ to 0.394$)$ & 0.752 \\
\hline Maternal job (yes vs. no) & $0.182(-0.164$ to 0.529$)$ & 0.302 & $0.089(-0.090$ to 0.268$)$ & 0.331 \\
\hline Family structure (two parents vs. single) & $0.270(-0.307$ to 0.846$)$ & 0.359 & $0.132(-0.166$ to 0.430$)$ & 0.386 \\
\hline Energy intake per a 1,000 kcal & $0.135(-0.355$ to 0.625$)$ & 0.588 & $0.136(-0.117$ to 0.389$)$ & 0.292 \\
\hline Fat $\%$ of energy intake per a percent & 0.041 (0.007 to 0.075$)$ & $0.017^{*}$ & $-0.007(-0.024$ to 0.011$)$ & 0.449 \\
\hline Meal skipping during a week (yes vs. no) & $-0.071(-0.131$ to -0.011$)$ & $0.020^{*}$ & $0.002(-0.029$ to 0.033$)$ & 0.884 \\
\hline Snack (yes vs. no) & 0.988 (0.582 to 1.393$)$ & $<0.001^{* * *}$ & 0.278 (0.066 to 0.490$)$ & $0.010^{* *}$ \\
\hline
\end{tabular}

BMI: body mass index, CI: confidential interval, KRW: Korean won.

${ }^{*} \mathrm{P}<0.05$. ${ }^{* *} \mathrm{P}<0.01$. ${ }^{* * *} \mathrm{P}<0.001$.

${ }^{\dagger}$ Adjusted for age (continuous), sex (male or female), sexual maturation at 4th year follow-up (Tanner stage I, II, III, IV, V), and variables in this table. ${ }^{\ddagger}$ Adjusted for age (continuous), sex (male or female), sexual maturation at 6th year follow-up (Tanner stage I, II, III, IV, V), baseline BMI (continuous), and variables in this table.

higher fat proportion of energy intake $(\mathrm{P}=0.017)$, regular meal consumption $(\mathrm{P}=0.020)$, and snack intake $(\mathrm{P}<0.001)$ were all significantly associated with a higher BMI of children $(\mathrm{P}<0.001)$. In the longitudinal analysis, higher maternal BMI $(\mathrm{P}=0.035)$, and frequent snack intake $(\mathrm{P}=0.010)$ were significant predictors of BMI increase during the 2-year follow-up (Table 4).

\section{Children's Body Mass Index Changes by Parental Obesity}

BMI increase over 2 years in 1 st grader group was 0.721 $\mathrm{kg} / \mathrm{m}^{2}$ in children with normal weight mothers, $0.989 \mathrm{~kg} / \mathrm{m}^{2}$ in those with overweight mothers, and $1,256 \mathrm{~kg} / \mathrm{m}^{2}$ in those with obese mothers. For the 4th grader group, BMI increases were $1.284 \mathrm{~kg} / \mathrm{m}^{2}, 1.135 \mathrm{~kg} / \mathrm{m}^{2}$, and $1.639 \mathrm{~kg} / \mathrm{m}^{2}$, respectively. There was no significant association between the degree of paternal obesity and children's BMI changes (Figure 2). 
A

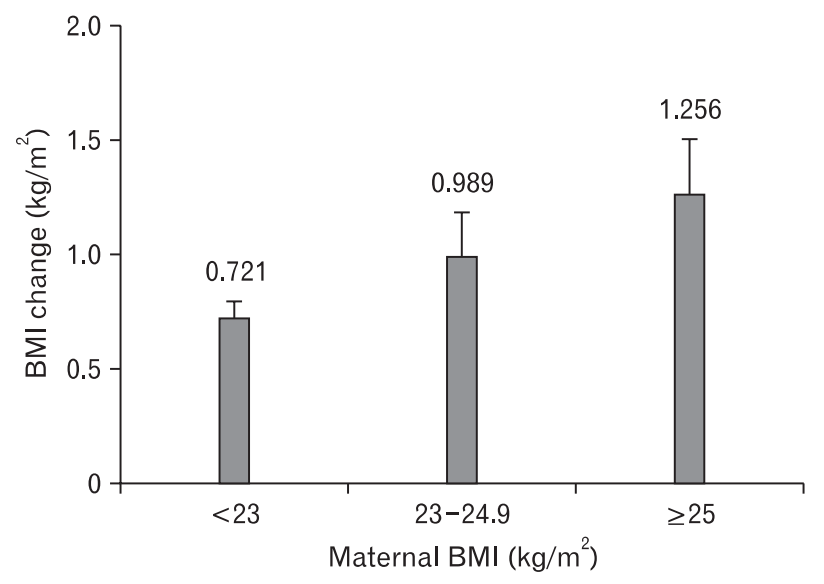

C

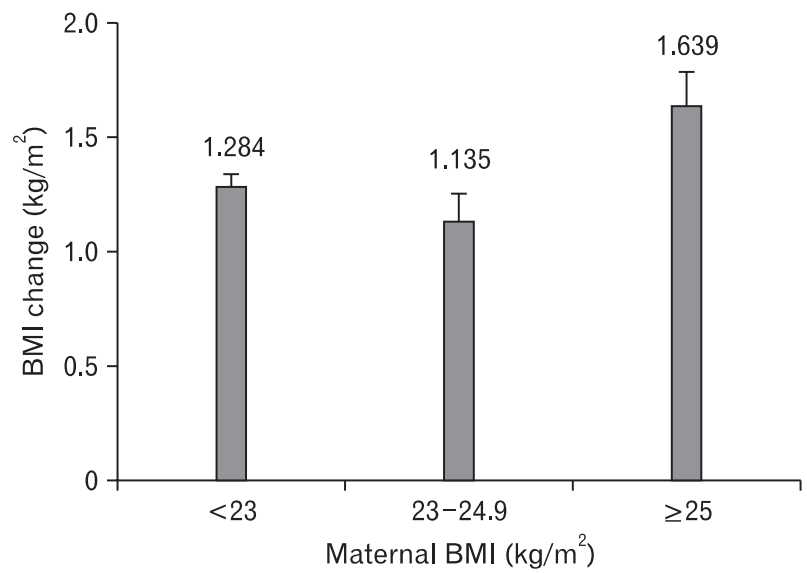

B

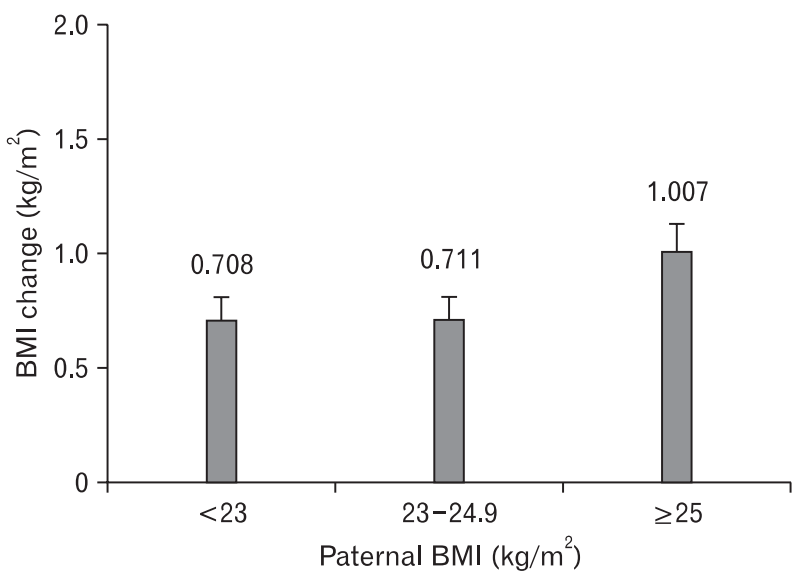

D

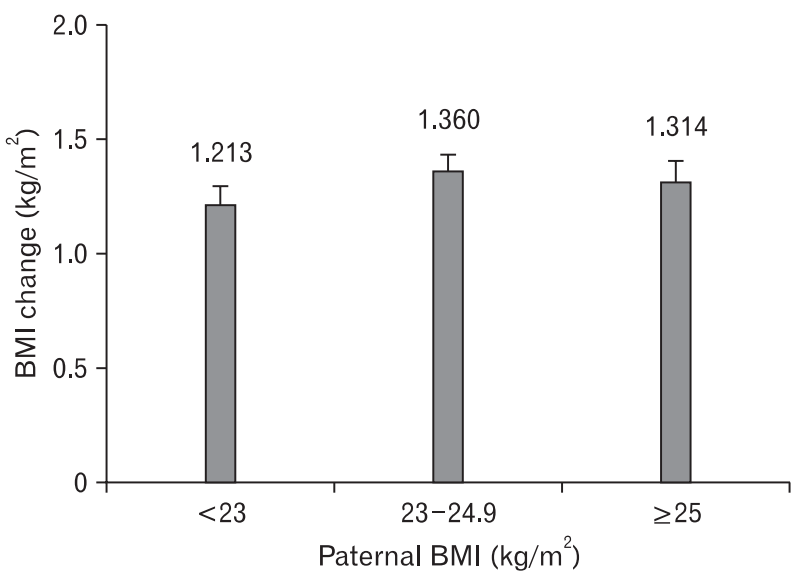

Figure 2. Estimated body mass index (BMI) changes over 2 years by parental BMI categories. The BMI changes were estimated by the general linear modeling controlling for age (continuous), sex (male or female), sexual maturation at 6th year follow-up (Tanner stage I, II, III, IV,V), baseline BMI (continuous), and variables in the Table 3 or Table 4. (A) 1st grader BMI change by maternal BMI categories, $\mathrm{P}=0.049$. (B) 1st grader BMI change by paternal BMI categories, $\mathrm{P}=0.118$. (C) 4 th grader BMI change by maternal BMI categories, $\mathrm{P}=0.025$. (D) 4 th grader BMI change by paternal BMI categories, $\mathrm{P}=0.359$. All $\mathrm{P}$-values are by general linear modeling. Error bars represent $+\mathrm{SE}$.

\section{DISCUSSION}

Here we assessed the factors associated with BMI of children in the 1st and 4th grade of elementary school in a cross-sectional study and further investigated factors that affect BMI changes in a longitudinal study over a 2-year period. Although there were some differences between the cross-sectional and the longitudinal study, parental BMI, sleep duration, household income, skipping meals, and snack intake were significantly associated with the baseline BMI and BMI changes over time in Korean children.

In particular, high parental BMI was identified as a strong risk factor for the high BMI of both 1st and 4th graders both in the cross-sectional and longitudinal study. This finding is consistent with previous observations from overseas countries that BMI of children positively correlates with BMI of their parents. ${ }^{14,15)}$ Genome-wide association studies identified variants at several loci associated with BMI, suggesting the influence of genetic predisposition in obesity. ${ }^{16)}$ Nonetheless, the rapid rise in obesity rate over the past few decades suggests environmental and behavioral factors as key determinants of obesity development over genetic predisposition. ${ }^{17)}$ Parents and their children are often exposed to similar environments and share similar lifestyles that are mainly determined by parents. ${ }^{18,19)}$ This is also supported by a recent cross-sectional study in Korea which showed that 2- to 12 -year-old children with obese parents $\left(B M I>25 \mathrm{~kg} / \mathrm{m}^{2}\right)$ were 4 times more likely to be obese themselves, ${ }^{11)}$ and our observation 
emphasizes parental obesity as a high-risk factor for childhood obesity.

Interestingly, effects of socioeconomic status (SES) on childhood obesity depend on the economical developmental status of countries. As such, obesity was more prevalent among children from low SES families in developed countries, whereas children of high SES in developing countries tend to be obese. ${ }^{20,21)}$ A recent domestic study reported a prevalence of obesity among children of lower SES in Korea, similar to developed countries. ${ }^{22)}$ Here again, both the longitudinal study with 1 st graders and the cross-sectional study in 4th graders showed an inverse relationship between household income and baseline BMI or BMI changes over time. The higher obesity rate in children of lower SES is thought to have several causes: 1) parents might be more generous and less controlling of dietary intake and habits of their children; 2) children might have easier access to high-calorie fast foods both within the home and in the local neighborhood; and 3 ) the access to safe playgrounds for physical activity might be limited. ${ }^{7)}$ In contrast, high SES with financial freedom allows better access to quality nutrition and environments that encourage healthy physical activity. ${ }^{23,24)}$

Short sleep duration per se is associated with obesity in children. ${ }^{25)}$ A possible explanation is that short sleep duration decreases nocturnal leptin production and increases ghrelin with a net effect of increasing appetite and fatigue, which in turn leads to higher caloric intake and reduced physical activity. ${ }^{26)}$ In this study, 1st grade children with a sleep duration of more than 9.5 hours per day showed a lower BMI by $0.5 \mathrm{~kg} / \mathrm{m}^{2}$ than children with 8.5 hours of sleep or less per day. The ideal sleep duration related to obesity is hard to define due to its dependence on children's developmental stage and different sociocultural influences. However, a significant linear dose-response relationship could be found in a meta-analysis; the pooled odds ratio for overweight/obesity was 0.91 (CI, 0.84 to 1.00) for each 1-hour increase in sleep duration. ${ }^{27)}$

Recent studies showed that snacking contributes to obesity. ${ }^{28,29)}$ The additional energy content of snacks leads to a positive energy balance as calorie intake with the next meal remains likely unchanged. ${ }^{29)}$ Interestingly, snacks lead to insulin secretion and suppress the late rise of free fatty acid in plasma that inhibits a feeling of satiety. ${ }^{26)}$ Our finding supports this, as even after adjusting for total energy intake, fat percent of energy intake, and meal regularity, snack intake was related with an increased BMI.
It is widely accepted that regular exercise is effective in preventing obesity in children and a lower level of physical activity is a risk factor for being overweight or obesity. ${ }^{30,31)}$ In contrast, our study showed that 1 st graders who did more physical exercise had a higher BMI increase during follow-up. This counterintuitive finding might be due to the following; 1) the study participants knew their outcome, obesity status. Hence overweight and obese children actually did more exercise to lose weight; 2) the amount of exercise participants did might not be enough to lose weight; 3) the definition of exercise this study used might be too broad to influence weight status.

This study has several limitations. First, a 2-year follow-up period might be too short to reliably detect the effects of lifestyle on obesity development, as children's anthropometric measures might not change dramatically over such a short period of time. In other studies, participants are followed more than five years. ${ }^{5,7)}$ As participants in the Obesity and Metabolic Disorders Cohort in Childhood will be followed up into their adulthood, longer follow-up data will be available soon. Second, data collection is mainly based upon unsupervised questionnaires on physical activity, dietary habit, pubertal staging, and nutrient intake, which may lead to information or reporting biases. Future research should incorporate biological markers such as accelerometer data for physical activity and blood nutrient levels to estimate nutrient intake, and actual physical examinations by trained personnel to assess pubertal staging, ${ }^{32)}$ as more reliable and accurate predictor variables. Third, even if it is a prospective longitudinal study, the predictor variables might be influenced by outcome variables, resulting in biologically implausible relationships such as the inverse correlation between exercise and BMI. Fourth, the number of study participants was relatively small for multivariate analysis and resulted in wide confidence intervals. Four different models showed similar trends but different results with a difficult interpretation. As longer follow-up is available, more concrete results will be expected.

Despite the above limitations, this preliminary study was the first to identify the factors associated with BMI changes in Korean children in a longitudinal study design and was able to identify the predictors of BMI increase in Korean children as parental obesity, short sleep duration, low social economic status, and frequent snacking. 


\section{CONFLICT OF INTEREST}

No potential conflict of interest relevant to this article was reported.

\section{REFERENCES}

1. de Onis M, Blossner M, Borghi E. Global prevalence and trends of overweight and obesity among preschool children. Am J Clin Nutr 2010;92:1257-64.

2. Oh K, Jang MJ, Lee NY, Moon JS, Lee CG, Yoo MH, et al. Prevalence and trends in obesity among Korean children and adolescents in 1997 and 2005. Korean J Pediatr 2008;51:9505.

3. Garn SM, LaVelle M. Two-decade follow-up of fatness in early childhood. Am J Dis Child 1985;139:181-5.

4. Epstein LH, Goldfield GS. Physical activity in the treatment of childhood overweight and obesity: current evidence and research issues. Med Sci Sports Exerc 1999;31(11 Suppl):S553-9.

5. Whitaker RC, Wright JA, Pepe MS, Seidel KD, Dietz WH. Predicting obesity in young adulthood from childhood and parental obesity. N Engl J Med 1997;337:869-73.

6. Gillman MW, Rifas-Shiman SL, Camargo CA Jr, Berkey CS, Frazier AL, Rockett HR, et al. Risk of overweight among adolescents who were breastfed as infants. JAMA 2001;285:2461-7.

7. Semmler C, Ashcroft J, van Jaarsveld CH, Carnell S, Wardle J. Development of overweight in children in relation to parental weight and socioeconomic status. Obesity (Silver Spring) 2009; 17:814-20.

8. Summerbell CD, Waters E, Edmunds LD, Kelly S, Brown $\mathrm{T}$, Campbell KJ. Interventions for preventing obesity in children. Cochrane Database Syst Rev 2005; (3):CD001871.

9. Oude Luttikhuis H, Baur L, Jansen H, Shrewsbury VA, O' Malley C, Stolk RP, et al. Interventions for treating obesity in children. Cochrane Database Syst Rev 2009;(1):CD001872.

10. Cho KY, Park H, Seo JW. The relationship between lifestyle and metabolic syndrome in obese children and adolescents. Korean J Pediatr Gastroenterol Nutr 2008;11:150-9.
11. Ko JA. Childhood obesity and familial environmental factor according to the developmental stages: the Korea NHANES study. J Korean Acad Fam Med 2008;29:939-47.

12. Kang JH, Park KH. Analysis of risk factors on obesity and combined metabolic disorders and establishment of cohort in childhood. Seoul: Inje University Industry-Academic Cooperation Foundation; 2010.

13. Korea Centers for Disease Control and Prevention; The Korean Pediatric Society; The Committee for the Development of Growth Standard for Korean Children and Adolescents. 2007 Korean Children and Adolescents Growth Standard. Seoul: Korea Centers for Disease Control and Prevention; 2007.

14. Svensson V, Jacobsson JA, Fredriksson R, Danielsson P, Sobko T, Schioth HB, et al. Associations between severity of obesity in childhood and adolescence, obesity onset and parental BMI: a longitudinal cohort study. Int J Obes (Lond) 2011;35:46-52.

15. Lake JK, Power C, Cole TJ. Child to adult body mass index in the 1958 British birth cohort: associations with parental obesity. Arch Dis Child 1997;77:376-81.

16. Loos RJ, Lindgren CM, Li S, Wheeler E, Zhao JH, Prokopenko I, et al. Common variants near MC4R are associated with fat mass, weight and risk of obesity. Nat Genet 2008;40:768-75.

17. Kivimaki M, Lawlor DA, Smith GD, Elovainio M, Jokela M, Keltikangas-Jarvinen L, et al. Substantial intergenerational increases in body mass index are not explained by the fetal overnutrition hypothesis: the Cardiovascular Risk in Young Finns Study. Am J Clin Nutr 2007;86:1509-14.

18. Simonen RL, Perusse L, Rankinen T, Rice T, Rao DC, Bouchard C. Familial aggregation of physical activity levels in the Quebec Family Study. Med Sci Sports Exerc 2002;34:1137-42.

19. Laskarzewski P, Morrison JA, Khoury P, Kelly K, Glatfelter L, Larsen R, et al. Parent-child nutrient intake interrelationships in school children ages 6 to 19: the Princeton School District Study. Am J Clin Nutr 1980;33:2350-5.

20. Wang Y. Cross-national comparison of childhood obesity: the epidemic and the relationship between obesity and socioeconomic status. Int J Epidemiol 2001;30:1129-36. 
21. Sobal J, Stunkard AJ. Socioeconomic status and obesity: a review of the literature. Psychol Bull 1989;105:260-75.

22. Kang HT, Ju YS, Park KH, Kwon YJ, Im HJ, Paek DM, et al. Study on the relationship between childhood obesity and various determinants, including socioeconomic factors, in an urban area. J Prev Med Public Health 2006;39:371-8.

23. Drewnowski A, Darmon N. The economics of obesity: dietary energy density and energy cost. Am J Clin Nutr 2005;82(1 Suppl):265S-73S.

24. Case A, Lubotsky D, Paxson C. Economic status and health in childhood: the origins of the gradient. Am Econ Rev 2002;92:1308-34.

25. Patel SR, Hu FB. Short sleep duration and weight gain: a systematic review. Obesity (Silver Spring) 2008;16:643-53.

26. Spiegel K, Tasali E, Penev P, Van Cauter E. Brief communication: Sleep curtailment in healthy young men is associated with decreased leptin levels, elevated ghrelin levels, and increased hunger and appetite. Ann Intern Med 2004;141:846-50.

27. Chen X, Beydoun MA, Wang Y. Is sleep duration associated with childhood obesity? A systematic review and metaanalysis. Obesity (Silver Spring) 2008;16:265-74.

28. Berteus Forslund H, Torgerson JS, Sjostrom L, Lindroos AK. Snacking frequency in relation to energy intake and food choices in obese men and women compared to a reference population. Int J Obes (Lond) 2005;29:711-9.

29. Chapelot D. The role of snacking in energy balance: a biobehavioral approach. J Nutr 2011;141:158-62.

30. Goran MI, Reynolds KD, Lindquist CH. Role of physical activity in the prevention of obesity in children. Int $\mathrm{J}$ Obes Relat Metab Disord 1999;23 Suppl 3:S18-33.

31. Hills AP, King NA, Armstrong TP. The contribution of physical activity and sedentary behaviours to the growth and development of children and adolescents: implications for overweight and obesity. Sports Med 2007;37:533-45.

32. Bonat S, Pathomvanich A, Keil MF, Field AE, Yanovski JA. Self-assessment of pubertal stage in overweight children. Pediatrics 2002;110:743-7. 